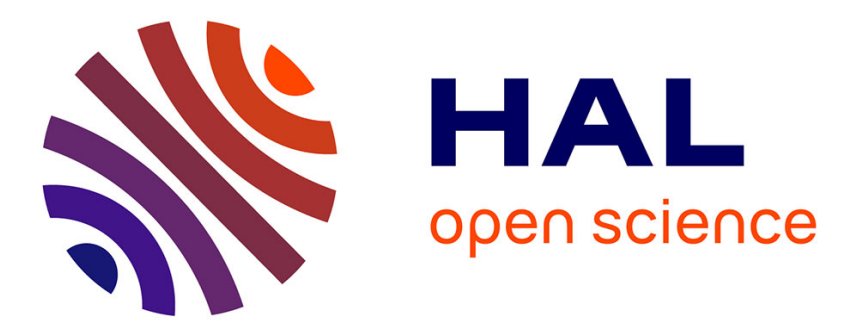

\title{
A Systematic Literature Review of the Hypomania Check List (HCL-32) for Adolescents: Relevance of Developmental Stage and Relationship Status during Screening
}

Robmarie López-Soto

\section{To cite this version:}

Robmarie López-Soto. A Systematic Literature Review of the Hypomania Check List (HCL-32) for Adolescents: Relevance of Developmental Stage and Relationship Status during Screening. 2021. hal-03190079

\section{HAL Id: hal-03190079 \\ https://hal.science/hal-03190079}

Preprint submitted on 6 Apr 2021

HAL is a multi-disciplinary open access archive for the deposit and dissemination of scientific research documents, whether they are published or not. The documents may come from teaching and research institutions in France or abroad, or from public or private research centers.
L'archive ouverte pluridisciplinaire HAL, est destinée au dépôt et à la diffusion de documents scientifiques de niveau recherche, publiés ou non, émanant des établissements d'enseignement et de recherche français ou étrangers, des laboratoires publics ou privés. 


\section{Prepublicaciones \\ OpenCiencia}

Prepublicaciones OpenCiencia

ISSN 2708-8693

Non peer-

www.prepublicaciones.org

OpenCiencia

https://doi.org/10.47073/preprints. 12

A Systematic Literature Review of the Hypomania Check List (HCL-32) for Adolescents:

Relevance of Developmental Stage and Relationship Status during Screening

Revisión de Literatura Sistemática Sobre el Uso de la Lista de Cotejo de Hipomanía (HCL-

32) con Adolescentes: Consideraciones sobre la Etapa del Desarrollo y Relaciones

Interpersonales durante la Evaluación

Robmarie López-Soto

Los Angeles, California, United States

Author Note

Robmarie López-Soto 는tps://orcid.org/0000-0002-0766-4171

The author is an independent scholar in the state of California. She has PhD in Clinical Psychology from Ponce Health Sciences University and an MA in Counseling Psychology from the Interamerican University of Puerto Rico. Her research interests include mood disorder assessment and mindfulness-based interventions. No funding was received for this review and there are no conflicts of interest to disclose.

Correspondence for this article should be addressed to Robmarie López-Soto at P.O. BOX 11006, Santa Ana, CA 92701. E-mail: robmarie.lopezsoto@gmail.com 


\section{Abstract}

A systematic literature review was conducted to assess the state of the evidence regarding use of the Hypomania Check List (HCL-32; Angst et al., 2005) with adolescents. Multiple databases were searched in English and Spanish using the terms "HCL-32 OR Hypomania Check List - 32 AND adolescents" and "Lista de Cotejo de Síntomas de Hipomanía AND adolescentes". Nonpeer reviewed studies, duplicates and irrelevant results were excluded. Reference sections of relevant studies were also searched. Eight studies met criteria for inclusion (Pooled sample $n=2245$ nonclinical, $62 \%$ female; Age $\left.M_{\text {pooled }}=17.38, \mathrm{SD}=.66\right)$. Used with adolescents, the HCL32 had psychometric properties comparable to adults. Non-clinical adolescent samples reported a significant number of risk-taking/irritability symptoms, regardless of gender. One study found that, when compared to an adult sample with bipolar disorder (BD) type II, adolescents in earlystage romantic love (ESIRL, $<8$ months) reported a comparable level of hypomanic symptoms that subsided with relationship duration $\left(M_{\text {pooled }}\right.$ duration $=10.824$ months). Finally, one study with a clinical sample of adolescents with eating disorders $(n=40)$ found a significant correlation between bulimia and BD. High heterogeneity across studies prevented a meta-analytic review. However, nonclinical elevations in risk-taking/irritability symptoms and ESIRL-related hypomania highlight the need to consider developmental stage and romantic relationship status while screening for BD. HCL-32 cut-off scores for adolescent populations should also be assessed. A brief screening model for ruling out clinical hypomania from ESIRL in adolescents is proposed.

Keywords: Bipolar disorder, hypomania, HCL-32, adolescent mental health, interpersonal relationships 


\section{Resumen}

Se completó una revisión de literatura sistemática para evaluar el uso de la "Lista de Cotejo de Síntomas de Hipomanía" (HCL-32) con muestras adolescentes. Se realizó una búsqueda bilingüe (inglés y español) utilizando los términos "HCL-32" OR "Hypomania Check List - 32" AND "adolescents" y "Lista de Cotejo de Síntomas de Hipomanía" AND "adolescentes". También se revisó la sección de referencia de los estudios incluidos ( $n=8$ estudios, $n$ muestra acumulada $=$ 2245 adolescentes no-clínicos, $62 \%$ féminas; $M$ acumulada edad=17.38, SD=.66). El HCL-32 mantuvo las propiedades psicométricas demostradas con muestras de adultos. En 5/8 estudios, los adolescentes en etapas tempranas de enamoramiento (ESIRL; $<8$ meses de relación) reportaron un alto número de síntomas hipomaníacos que tendió a mermar con el tiempo ( $M$ tiempo de merma=10.824 meses). Los adolescentes reportaron un alto número de síntomas de irritabilidad y toma de riesgos, independientemente de estado interpersonal. Por otra parte, un estudio con muestra clínica ( $\mathrm{n}=40$ adolescentes con trastornos alimenticios) encontró una correlación significativa entre la bulimia y la depresión bipolar. La alta heterogeneidad de los estudios previno el metaanálisis de los resultados. No obstante, se recomienda reconsiderar las puntuaciones de corte óptimas del HCL-32 para adolescentes. Además, aquellos en etapas tempranas de enamoramiento reportan un número de síntomas similar a los adultos con depresión bipolar tipo II, lo cual pudiera resultar en diagnósticos confusos sin el escrutinio necesario. Se propone un modelo de tamizaje para discriminar entre estados de hipomanía clínicos o un estado propio del ESIRL en adolescentes.

Palabras clave: HCL-32, hipomanía, depresión bipolar, salud mental en adolescentes, relaciones interpersonales 


\section{A Systematic Literature Review of the Hypomania Check List (HCL-32) for Adolescents: Relevance of Developmental Stage and Relationship Status During Screening}

The Hypomania Check List - 32 (HCL-32; Angst et al., 2005) is a self-rated instrument to screen for bipolar disorder (BD) in individuals with depression. It was validated with adult outpatients: An Italian sample ( $\mathrm{n}=186$ participants, $61 \%$ female; 62 Major Depressive Disorder [MDD], 27 BD-I, 97 BD-II) and a Swedish sample (n=240 participants, 58.8\% female; 98 MDD, 75 BD-I, 67 BD-II). In this study, a cut-off score of 14 offered the most balance between sensitivity (80\%) and specificity (51\%), with a positive predictive power of $73 \%$ and a negative predictive power of $61 \%$. Similar results were found for the HCL-32-R2, a revised version of the instrument (Fornaro et al., 2015), where the cut-off score of 14 had an improved sensitivity of $89 \%$ and a specificity of $79 \%$. Current mood state is assessed in the HCL-32 with a 7-point Likert scale that ranges from "Much worse than usual" to "Much better than usual", with little to no impact in self-assessment accuracy (Angst et al., 2005).

The HCL-32 can also be used to screen for clinical hypomania at lower cut-off points, with increased sensitivity and comparable specificity. A cut-off score of 8 effectively screened for hypomania with a sensitivity of $92 \%$ and a specificity of $48 \%(\mathrm{AUC}=.76)$ in a sample of adult Taiwanese outpatients ( $n=59,39$ female) diagnosed with MDD (Chou et al., 2012). Similarly, Wu et al. (2008) found that a cut-off score of 9 offered higher sensitivity (91\%) and acceptable specificity (46\%) in a sample of 199 adult Chinese outpatients (Wu et al., 2008). In this regard, lower cut-off points that prioritize sensitivity are best utilized in clinical settings, where the goal is to identify at-risk individuals for timely intervention (Zimmerman \& Holst, 2018). 
The HCL-32 has two distinct, primary subscales: An "Active/Elated" (A/E) and a "RiskTaking/Irritability" (RT/I) subscale. The A/E subscale refers to a cluster of symptoms known as "Bright Hypomania", which include elevated mood, increased activity and flexible thinking (Angst et al., 2005). Conversely, the RT/I subscale, also known as "Dark Hypomania", is a cluster of items commonly associated with BD functional impairment: increased anger/irritability, hostile or risk-taking behavior (i.e. impulsive spending) and cognitive dysfunction, such as flight of ideas. Irritable hypomanic states tend to be more common in BD and more pervasive in later stages of the illness. With a cut-off score of 3, the RT/I subscale was able to discriminate between BD-I and MDD in one of the validation samples. However, it failed to consistently discriminate between BD and MDD in the combined sample (Angst et al., 2005).

There is strong evidence for the validity and reliability of the HCL-32 for screening BD in adults with depression (Meyer et al., 2014). However, most studies with the HCL-32 have been completed with adult samples. This is understandable, as it takes approximately 10 years to for $\mathrm{BD}$ to be accurately diagnosed. On the other hand, staging models of $\mathrm{BD}$ point to biosocial indicators of the illness at earlier stages. According to Duffy (2012), comorbid neurodevelopmental conditions such as attention deficit and hyperactivity disorder (ADHD), learning disorders, as well as increased anxiety and irritable states are risk factors for BD. A family history of BD is also one of the strongest predictors for BD. Taken together, these factors indicate the need to consistently screen for BD in younger populations. With its good validity and reliability, the HCL-32 is a potentially useful instrument for use with youth, though less is known about its properties with pediatric populations.

Adolescence as a developmental stage is particularly relevant to BD because of its physiological and psychosocial processes. For instance, synaptic pruning - a neuroplastic 
process where synaptic pathways are modified en masse through apoptosis - can interact with genetic risk and psychological vulnerability factors such as trauma to increase the likelihood of early illness onset. In turn, early illness onset is associated to more severe mood disorder outcomes such as marked functional impairment, recurrent hospitalizations, and increased medical comorbidity (Duffy, 2014). As such, understanding the screening properties of the HCL32 for adolescent populations and its idiosyncrasies with this population can improve screening and targeted screening and therapeutic targets during the "at-risk" or initial stages. To this end, the goal of this literature review was two-fold: 1) Identify the state of the psychometric evidence for HCL-32 use with adolescents, 2) Identify clinical and psychosocial issues specific to adolescents as identified by the HCL-32.

\section{Method}

A systematic database search was conducted from September 2019 to April 2020 in Google Scholar, PubMed, Medline, Psychiatry Online, PSYCHInfo and SCIelo, using the following search terms and Boolean operators: "Hypomania Check List - 32" OR "HCL-32" AND "adolescents" OR "Lista de Cotejo de Síntomas de Hipomanía" AND "adolescentes". No clinical diagnosis was specified, or publication date range was set to maximize search results and potential avenues for analysis and discussion. Studies were included if they: 1) Included the HCL-32 in data collection procedures, 2) Samples were restricted to adolescents (Age Range: 13-17 years old), or 3) The HCL-32 was administered during adolescence, be it in a crosssectional, cross-sectional with multiple time points or longitudinal study). The initial search yielded 960 results. Peer-reviewed articles, abstracts or posters, and studies that assessed modified versions of the HCL-32 were included. Initially, search results that were thematically irrelevant to the search criteria (i.e. referenced but did not actually utilize the HCL-32 during 
data collection), non-peer reviewed publications, book chapters, and non-English or Spanish articles were excluded, reducing the total number of studies to 490 articles. Next, repeated results, studies with adults (participants older than 18 years of age) or mixed adolescent-adult samples without distinct categories of either were excluded. Notably, six retrospective, longitudinal studies were excluded during this phase of review because participants completed the HCL-32 as adults. Eight studies were included in the final sample. Pooled means for age were calculated by multiplying the mean age for each study by each sample size and dividing the result by the sum of the sample size. Effect sizes (Cohen's $d$ ) for intergroup differences in HCL32 total scores were calculated according to the method proposed by Thalheimer \& Cook (2002). Due to limited availability of the data, effect sizes for three studies were not calculated. A summary table of sociodemographic and review findings can be found in Appendix A.

\section{Results}

\section{Study and Cumulative Sample Characteristics}

The pooled sample consisted of 2285 predominantly nonclinical and female adolescents (98.2\% nonclinical, $n=969$ female, age $M_{\text {pooled }}=17.38, \mathrm{SD}=.66$ ). One study had a clinical sample of adolescent inpatients with eating disorders $(n=40,1.8 \%$ of the total pooled sample). All studies were cross-sectional, and one of these performed a follow-up at 8 months. Studies were classified according to their main outcomes: 1) Psychometric Properties (2/8; cumulative $n=1694,57.2 \%$ female); 2) Romantic Love Hypomania (5/8; cumulative $n=551,65.5 \%$ female); and 3) Emotion Dysregulation in Eating Disorders $(1 / 8 ; n=40)$. While a meta-analysis of the romantic love hypomania studies was initially considered, the high heterogeneity of the sample prevented additional analysis $\left(Q(7)=181.752, \operatorname{tau}^{\wedge} 2=19.339, \mathrm{I}^{\wedge} 2=96.149, p<.001\right)$. 


\section{Narrative Summary of the Findings $(n=8)$}

\section{HCL-32: Psychometric Properties for Adolescent Samples (n=2)}

According to Holtmann et al. (2009), the internal factor structure of the HCL-32 was assessed with a sample of 294 nonclinical adolescents ( $M$ age range $=15.3-20.4$ years old). A moderate mean difference in total HCL-32 scores emerged between hypomanic and nonhypomanic adolescent groups (Cohen's $d=0.58$ ). Factor analysis produced a three-factor structure: An Active/Elated (A/E) factor and a Risk-Taking/Irritability (RT/I) factor that has two sub-factors: 1) Disinhibited/Stimulation-Seeking (D/SS) and 2) Irritable-Erratic (I-E). Elevated scores in the $\mathrm{A} / \mathrm{E}$ dimension were associated with higher HCL-32 total scores and disinhibition. High scores in the D/SS and I-E sub-categories were indicative of externalizing problems: substance abuse, attention deficit and hyperactivity disorder (ADHD) and conduct disorder (CD), which can point to early-onset BD (Holtmann et al., 2009).

Similarly, Hosang, Cardno, Freeman \& Ronald (2017) conducted assessed the underlying structure of the HCL-16, a shortened version of the HCL-32, with a principal components analysis and tested its validity for screening BD in adolescents ( $n=1400$ non-clinical adolescents, $M$ age=17.05, SD=.88). The HCL-16 had two factors: A/E and RT/I. RT/I was more strongly related to psychopathology: psychotic experiences, internalizing/externalizing problems, and reduced life satisfaction. However, adolescents with a family history of BD had increased total and $\mathrm{A} / \mathrm{E}$ scores (Hosang et al., 2017).

\section{HCL-32: Differentiation of Romantic Love from BD Hypomania (n=5)}

According to Brand et al. (2007), this cross-sectional study with 107 non-clinical adolescents $(M$ age $=17.98, \mathrm{SD}=1.33)$ assessed the effect of romantic relationships on mood and 
behavior ( $n=60$ adolescents recently in love; 47 longer-lasting romantic relationships or single).

Participants with psychiatric disorders were excluded (see Table 2). Strong and significant mean differences (MD=6.41, Cohen's $d=1.01$ ) were found for adolescents in early-stage intense romantic love (ESIRL $M$ duration=5.3 months, $\mathrm{SD}=6.78$ ) and adolescents not in love or in longterm relationships ( $M$ long-term relationship duration=13.08 months, $\mathrm{SD}=16.50)$. ESIRL adolescents also reported more positive mood states in the mornings and in the evenings, a decreased need for sleep and better daytime concentration than controls. Sleep patterns stabilized as the relationship shifted to companionate love. ESIRL also reported a greater sense of selfcontrol than their long-term relationship counterparts, along with feeling more energetic and physically active during the day. Functional impairment was associated with romantic love intensity in the Yale Brown Obsessive-Compulsive Scale (Y-BOCS). The authors concluded that the cognitive and sleep-related shifts experienced by adolescents during ESIRL were comparable to BD-II hypomania in adults (Brand et al., 2007), although the effect size was small (Cohen's $d=-0.27)$.

In a follow-up study, Brand, Angst, \& Holsboer-Trachsler (2010) assessed gender differences in ESIRL adolescent groups. Participants with psychiatric disorders were excluded. Female adolescents in ESIRL reported more hypomanic symptoms than males, but all adolescents in ESIRL ( $n=60 ; M$ relationship duration=5.3 months, $\mathrm{SD}=6.78$ ) endorsed HCL-32 scores comparable to a comparison sample of adult outpatients with BD-II (Angst et al., 2005; Brand et al., 2010). Both ESIRL and controls ( $n=47)$ had higher scores in the RT/I dimension compared to adults. According to the authors, high RT/I score may reflect developmentally adaptive, autonomy-promoting attitudes among adolescents. 
In a later study by Bajoghli et al. (2011), female adolescents $(n=86, M$ age $=17.97$, $\mathrm{SD}=1.09)$ within the in-love group ( $n=38$ in love; $M$ relationship duration=10.10 months, $\mathrm{SD}=5.84$; relationship duration range: 4-14 months) reported more hypomanic symptoms (HCL$32 M$ score $=15.97, \mathrm{SD}=4.16)$ than controls $(n=48$ not in love; HCL-32 $M$ score $=10.48$, $\mathrm{SD}=4.37$ ). The effect size of the inter-group mean difference was strong (Cohen's $d=1.28$ ). Participants in love also reported increased physical activity, more positive moods, and no changes in sleep quality (Bajoghli et al., 2011). There was a moderate, positive correlation between hypomanic symptoms and relationship duration $(r=.44, p<.01)$.

In a second study by Bajoghli et al. (2013), adolescents in love ( $n=81, M$ relationship duration=10.66 months, $\mathrm{SD}=7.40$ ) reported more hypomanic and less depression symptoms than controls. Furthermore, there was a significant gender difference in total scores: female adolescents in love reported significantly more hypomanic symptoms than males $(F(1,197)$ $=.006, p=.006$.). Increased state anxiety was also reported by adolescents in love in the StateTrait Anxiety Inventory (STAI). However, no significant changes in sleep quality were found by the authors, who suggested that changes in sleep quality can potentially differentiate between clinical hypomanic symptoms from romantic love states in adolescents (Bajoghli et al., 2013).

In a follow-up study by Bajoghli et al. (2017), romantic love states ( $n=45$ still in love, 69 still not in love, 17 recently in love and 19 no longer in love) were significantly associated with more hypomanic symptoms at 8 months, though symptoms decreased with relationship duration. A large 6-point difference in mean HCL-32 scores was found in adolescents who reported being newly in love at the 8-month follow-up (Cohen's $d=2.97$ ). Contrary to sleep quality findings, mood and anxiety symptoms increased while recently in love. Sociocultural factors such as 
parental approval, romantic or sexual conflicts, or arousal interpreted as anxiety can potentially mediate this association (Bajoghli et al., 2017).

\section{HCL-32 and Emotion Dysregulation in Eating Disorders $(n=1)$}

As published in a peer-reviewed poster, Vargas-Castro, Grau, Faus, \& Sanchez-Povedano (2015) assessed emotion dysregulation and eating habits in a cross-sectional study with a sample of adolescents with eating disorders ( $\mathrm{ED} n=40$; Age range=12-19 years old). Adolescents with anorexia nervosa (AN $n=17$ ) endorsed more hypomanic symptoms on the HCL-32 than adolescents with bulimia nervosa ( $\mathrm{BN} n=23)$, but only $\mathrm{BN}$ scores correlated positively with lack of inhibition, self-control and attentional capacity on the Barcelona-Bipolar Eating Disorder Scale (BEDS), suggesting that BN may be more strongly related to BD (Vargas Castro et al., 2015).

\section{Discussion}

The present review was completed to assess the current state of the literature regarding the use of the HCL-32 for screening BD in adolescents. A systematic database search and literature review yielded 8 relevant studies: 2/8 assessed HCL-32 psychometric properties with adolescent samples, 5/8 assessed the hypomanic-like qualities of romantic love in adolescents, and 1/8 assessed emotion dysregulation in adolescent inpatients with ED. In all studies, the HCL32 identified significant differences between control and target group samples. Holtmann et al. (2009) found that the HCL-32 maintained its psychometric properties with adolescents. Additionally, they found a three-factor solution, where RT/I divided into Disinhibition/Stimulation-Seeking and Irritable-Erratic dimensions, that can potentially improve diagnostic specificity for adolescents. Furthermore, adolescents with increased active/elated 
symptoms are at risk for poor treatment seeking and adherence since they tend to view their symptoms as less pathological (Hosang et al., 2017).

\section{Adolescents in Love Endorsed More Symptoms on the HCL-32}

Female adolescents in love reported significantly more symptoms than their male counterparts (Bajoghli et al., 2013; Brand et al., 2010). However, a subset reported more hypomanic-like symptoms as relationship duration increased (Bajoghli et al., 2013). These gender differences possibly reflect distinct biopsychosocial attachment processes between female and male adolescents, as higher HCL-32 scores were found in adolescent female groups, regardless of ethnicity. Relationship duration, while informative of sentimental status and relationship goals, does not necessarily reflect attachment style or relationship dynamics. An insecure and preoccupied attachment style often underlies mood disorders: "For preoccupied persons, the primary goal is to maintain closeness with the partner at all costs and divert attention away from the problem, the solving of which can paradoxically cause the partner to withdraw attention" (Wendołowska et al., 2020). Although relationship quality and attachment style were not assessed in these studies, increased anxiety symptoms along with increased mood symptoms could have also emerged from preoccupation with social and interpersonal goals. In BD, elevated mood and hyperpositive affect have been associated with an increased need to win within a social context (Gilbert et al., 2007), while the association between major life events and bipolar mood episodes is well-documented across the literature. In support of this theory, Brand et al. (2007) found that adolescents with functional impairment were more likely to have experienced stronger ESIRL and higher HCL-32 scores (Brand et al., 2007). Mismatched expectations and diverging communication styles can contribute to a dysphoric mood by reinforcing insecure 
attachment schemas. Concurrent assessment of personality traits and attachment styles can inform future studies and mood-management interventions for adolescents.

Adolescents in Love Experienced Increased State Anxiety. Four out of seven (4/7) studies included an instrument to assess concurrent anxiety symptoms. Bajoghli et al. (2013, 2017) found that adolescents in love experienced significant state anxiety, regardless of gender. Furthermore, anxiety severity was independent of depression symptoms. Thus, sociocultural factors, such as parental disapproval, potentially mediate this association since adolescents learn to conceal symptoms as a function of social acceptance (MacLean et al., 2010). In adults, anxiety disorders are highly comorbid with $\mathrm{BD}$ and associated with a more severe course of illness that includes marked functional impairment, substance abuse, and increased suicidality (Simon et al., 2004). Allostatic load theory suggests that frequent exposure to stressful or traumatic events increases neurophysiological sensitivity to stress, increasing the likelihood of a bipolar mood episode and progressive declines in systemic health (Grande et al., 2012; Kapczinski et al., 2008; POST et al., 2001). As such, future studies of romantic love and anxiety in at-risk and initialstage adolescents are especially relevant for early interventions.

\section{Adolescents in Love Conserved Sleep Quality with Reduced Hours. A reduced need}

for sleep is a prodromal manic symptom. Therefore, marked changes in sleep pattern can differentiate de facto BD onset from subclinical active or elated moods. Brand et al. (2007) found an association between ESIRL and significant reductions in sleep hours with no decline in sleep quality, which is often considered a prodromal symptom of mania. Relatedly, Hosang, Cardno, Freeman, \& Ronald (2017) found a positive association between sleep problems, HCL16 total scores and increased markers of psychopathology. These findings support the wellevidenced association between hypomania and sleep problems within adolescent samples. 


\section{Increased HCL-32 Scores in Adolescents with Bulimia}

Vargas-Castro, Grau, Faus, \& Sánchez-Povedano (Vargas Castro et al., 2015) used the HCL-32 to assess emotion dysregulation in adolescent inpatients with severe ED. Though both groups with ED had significant HCL-32 scores, bulimia was more strongly associated to BD than anorexia. The association between bulimia and BD is well evidenced (Amianto et al., 2011). However, less is known about anorexia and possible BD. Given that many components of the RT/I subscale are meant to assess dysphoric mood, this subscale possibly provides a preliminary index of emotion dysregulation problems in anorexia.

\section{Clinical Implications}

Findings support the validity and reliability of the HCL-32 to identify hypomanic symptoms in adolescents, though additional studies with larger sample sizes are warranted. A series of studies which assessed the impact of relationship status on hypomanic mood support the need to routinely assess social and interpersonal events as risk factors for mood disorders. Concurrent assessment with the Y-BOCS can be used to discriminate between subclinical hypomania and ESIRL intensity by also considering the degree of functional impairment. Finally, significant disruptions in sleep pattern and binge eating habits in adolescents can point to an early-stage BD as opposed to a psychosocial event such as ESIRL. Because adolescents tend to report a high number of symptoms on the RT/I subscale, cut-off scores should be reassessed for this population. Questions about relationship status can be assessed with a semi-structured interview during the second phase of the screening process, where a more thorough approach is warranted (Zimmerman \& Holst, 2018). A brief screening intervention for adolescents is outlined in Figure 2. 


\section{Limitations}

This review was completed to assess the state of the literature regarding use of the HCL32 with adolescents. As such, a review of studies with more inclusive parameters can determine if these findings are reproducible with other screening instruments, such as the MDQ. While most studies were completed with nonclinical adolescents, results from this review can inform future studies of romantic love and anxiety in adolescents with psychiatric disorders and screening interventions for nonclinical adolescent samples.

\section{Conclusion}

The HCL-32 can be used to screen hypomanic symptoms in adolescents. However, the neurophysiological and developmental processes of adolescence can impact the number of symptoms reported in the HCL-32. Nonclinical adolescents tend to report an increased number of risk-taking/irritability symptoms and those in early-stage romantic love (ESIRL) experience significant anxiety and mood elevation. These findings can inform future studies as well as clinical and public health policy interventions that target adolescent mental health and wellbeing. 


\section{References}

Amianto, F., Lavagnino, L., Leombruni, P., Gastaldi, F., Daga, G. A., \& Fassino, S. (2011). Hypomania across the binge eating spectrum. A study on hypomanic symptoms in full criteria and sub-threshold binge eating subjects. Journal of Affective Disorders, 133(3), 580-583. https://doi.org/10.1016/j.jad.2011.04.049

Angst, J., Adolfsson, R., Benazzi, F., Gamma, A., Hantouche, E., Meyer, T. D., Skeppar, P., Vieta, E., \& Scott, J. (2005). The HCL-32: Towards a self-assessment tool for hypomanic symptoms in outpatients. Journal of Affective Disorders, 88(2), 217-233. https://doi.org/10.1016/j.jad.2005.05.011

Bajoghli, H., Farnia, V., Joshaghani, N., Haghighi, M., Jahangard, L., Ahmadpanah, M., Bahmani, D. S., Holsboer-Trachsler, E., \& Brand, S. (2017). ”I love you forever (More or less)"-stability and change in adolescents' romantic love status and associations with mood states. Revista Brasileira de Psiquiatria, 39(4), 323-329. https://doi.org/10.1590/1516-

\section{$\underline{4446-2016-2126}$}

Bajoghli, H., Joshaghani, N., Gerber, M., Mohammadi, M. R., Holsboer-Trachsler, E., \& Brand, S. (2013). In Iranian female and male adolescents, romantic love is related to hypomania and low depressive symptoms, but also to higher state anxiety. In International Journal of Psychiatry in Clinical Practice (Vol. 17, Issue 2, pp. 98-109).

\section{https://doi.org/10.3109/13651501.2012.697564}

Bajoghli, H., Joshaghani, N., Mohammadi, M. R., Holsboer-Trachsler, E., \& Brand, S. (2011). In female adolescents, romantic love is related to hypomanic-like stages and increased physical activity, but not to sleep or depressive symptoms. International Journal of 
Psychiatry in Clinical Practice, 15(3), 164-170.

https://doi.org/10.3109/13651501.2010.549340

Brand, S., Angst, J., \& Holsboer-Trachsler, E. (2010). Is the increase of hypomanic stages during adolescence related to gender and developmental tasks? In World Journal of Biological Psychiatry (Vol. 11, Issue 3, pp. 594-602). https://doi.org/10.3109/15622970903521149

Brand, S., Luethi, M., von Planta, A., Hatzinger, M., \& Holsboer-Trachsler, E. (2007). Romantic Love, Hypomania, and Sleep Pattern in Adolescents. Journal of Adolescent Health, 41(1), 69-76. https://doi.org/10.1016/j.jadohealth.2007.01.012

Chou, C. C., Lee, I. H., Yeh, T. L., Chen, K. C., Chen, P. S., Chen, W. T., Lu, R.-B., \& Yang, Y. K. (2012). Comparison of the validity of the Chinese versions of the Hypomania Symptom Checklist-32 (HCL-32) and Mood Disorder Questionnaire (MDQ) for the detection of bipolar disorder in medicated patients with major depressive disorder. International Journal of Psychiatry in Clinical Practice, 16(2), 132-137. https://doi.org/10.3109/13651501.2011.644563

Duffy, A. (2014). Toward a comprehensive clinical staging model for bipolar disorder: Integrating the evidence. Canadian Journal of Psychiatry, 59(12), 659-666. https://doi.org/10.1177/070674371405901208

Fornaro, M., Elassy, M., Mounir, M., Abd-Elmoneim, N., Ashour, H., Hamed, R., Al-Shehri, A., Bedir, S., Rashed, I., Amer, N., Mohammed, T. A., De Berardis, D., Mazza, M., Pino, M., Koshy, A. S., De Pasquale, C., Okasha, T., \& Angst, J. (2015). Factor structure and reliability of the Arabic adaptation of the Hypomania Check List-32, second revision (HCL32-R2). Comprehensive Psychiatry, 59, 141-150. 


\section{https://doi.org/10.1016/j.comppsych.2015.02.015}

Gilbert, P., McEwan, K., Hay, J., Irons, C., \& Cheung, M. (2007). Social rank and attachment in people with a bipolar disorder. Clinical Psychology and Psychotherapy, 14(1), 48-53. https://doi.org/10.1002/cpp.508

Grande, I., Magalhães, P. V, Kunz, M., Vieta, E., \& Kapczinski, F. (2012). Mediators of allostasis and systemic toxicity in bipolar disorder. Physiology \& Behavior, 106(1), 46-50. https://doi.org/10.1016/j.physbeh.2011.10.029

Holtmann, M., Pörtner, F., Duketis, E., Flechtner, H. H., Angst, J., \& Lehmkuhl, G. (2009). Validation of the Hypomania Checklist (HCL-32) in a nonclinical sample of German adolescents. Journal of Adolescence, 32(5), 1075-1088. https://doi.org/10.1016/j.adolescence.2009.03.004

Hosang, G. M., Cardno, A. G., Freeman, D., \& Ronald, A. (2017). Characterization and structure of hypomania in a British nonclinical adolescent sample. Journal of Affective Disorders, 207(April 2016), 228-235. https://doi.org/10.1016/j.jad.2016.08.033

Kapczinski, F., Vieta, E., Andreazza, A. C., Frey, B. N., Gomes, F. A., Tramontina, J., KauerSant'Anna, M., Grassi-Oliveira, R., \& Post, R. M. (2008). Allostatic load in bipolar disorder: Implications for pathophysiology and treatment. Neuroscience \& Biobehavioral Reviews, 32(4), 675-692. https://doi.org/10.1016/j.neubiorev.2007.10.005

MacLean, A., Sweeting, H., \& Hunt, K. (2010). 'Rules' for boys, 'guidelines' for girls: Gender differences in symptom reporting during childhood and adolescence. Social Science \& Medicine, 70(4), 597-604. https://doi.org/10.1016/j.socscimed.2009.10.042 
Meyer, T. D., Schrader, J., Ridley, M., \& Lex, C. (2014). The Hypomania Checklist (HCL) Systematic review of its properties to screen for bipolar disorders. Comprehensive Psychiatry, 55(5), 1310-1321. https://doi.org/10.1016/j.comppsych.2014.03.002

POST, R. M., LEVERICH, G. S., XING, G., \& WEISS, S. R. B. (2001). Developmental vulnerabilities to the onset and course of bipolar disorder. Development and Psychopathology, 13(3), 581-598. https://doi.org/10.1017/S0954579401003091

Simon, N. M., Otto, M. W., Wisniewski, S. R., \& Fossey, M. (2004). Anxiety Disorder Comorbidity in Bipolar Disorder Patients : Data From the Firs ... American Journal of Psychiatry, 161, 2222-2229. https://doi.org/10.1176/appi.ajp.161.12.2222

Thalheimer, W., Cook, S. (2002). How to calculate effect sizes from published research: A simplified methodology. Retrieved from http://work-learning.com/effect_sizes.htm

Vargas Castro, J. A., Grau, T., Faus, G., \& Sánchez Povedano, M. (2015). Emotional Dysregulation in Adolescents, a Common Potential Denominator Between Eating Disorders and Bipolar Spectrum. European Psychiatry, 30, 1184. https://doi.org/10.1016/s0924$\underline{9338(15) 31995-7}$

Wendołowska, A., Czyżowska, D., \& Siwek, M. (2020). The dyadic coping model of bipolar disorder patients. Psychiatria Polska, 2674(172), 1-16. https://doi.org/10.12740/pp/onlinefirst/118840

Wu, Y.-S., Angst, J., Ou, C.-S., Chen, H.-C., \& Lu, R.-B. (2008). Validation of the Chinese version of the Hypomania Checklist (HCL-32) as an instrument for detecting hypo(mania) in patients with mood disorders. Journal of Affective Disorders, 106(1), 133-143. 
https://doi.org/10.1016/j.jad.2007.06.004

Zimmerman, M., \& Holst, C. G. (2018). Screening for psychiatric disorders with selfadministered questionnaires. Psychiatry Research, 270, 1068-1073.

https://doi.org/10.1016/j.psychres.2018.05.022 


\section{Appendix A: Tables and Figures}

\section{Table A1}

Sample Characteristics for Each of the Studies ( $n=8)$

\begin{tabular}{|c|c|c|c|c|c|}
\hline Authors & Country & $\begin{array}{l}\text { Sample Size } \\
(\text { Female } N)\end{array}$ & $M$ age (SD) & Population & $\begin{array}{l}\text { Relationship } \\
\text { Status }\end{array}$ \\
\hline $\begin{array}{l}\text { Holtmann et al. } \\
\text { (2009) }\end{array}$ & Germany & 294 (139) & $17.3(\mathrm{SD}=1.1)$ & $\begin{array}{l}\text { Nonclinical - } \\
\text { Students ( } n=5 \\
\text { schools in } \\
\text { Cologne) }\end{array}$ & Not Reported \\
\hline $\begin{array}{l}\text { Hosang, Cardno, } \\
\text { Freeman, \& Ronald } \\
\text { (2017) }\end{array}$ & England & $1400(830)$ & $17.05(\mathrm{SD}=.88)$ & $\begin{array}{l}\text { Nonclinical - } \\
\text { Siblings of } \\
\text { twins from } \\
\text { TEDS/LEAP } \\
\text { study }\end{array}$ & Not Reported \\
\hline Brand et al. (2007) & Switzerland & $107(72)$ & $\begin{array}{l}17.95 \\
(\mathrm{SD}=1.34)\end{array}$ & $\begin{array}{l}\text { Nonclinical - } \\
\text { Early-Stage } \\
\text { Romantic Love } \\
\text { (ESIRL)/Not in } \\
\text { Love }\end{array}$ & $\begin{array}{l}\text { ESIRL } M \\
\text { duration=5.3 } \\
\text { months } \\
\text { (SD=6.78 } \\
\text { months); Long- } \\
\text { Term } \\
\text { Partnership } M \\
\text { duration=13.08 } \\
\text { months } \\
\text { (SD=16.50 }\end{array}$ \\
\hline
\end{tabular}




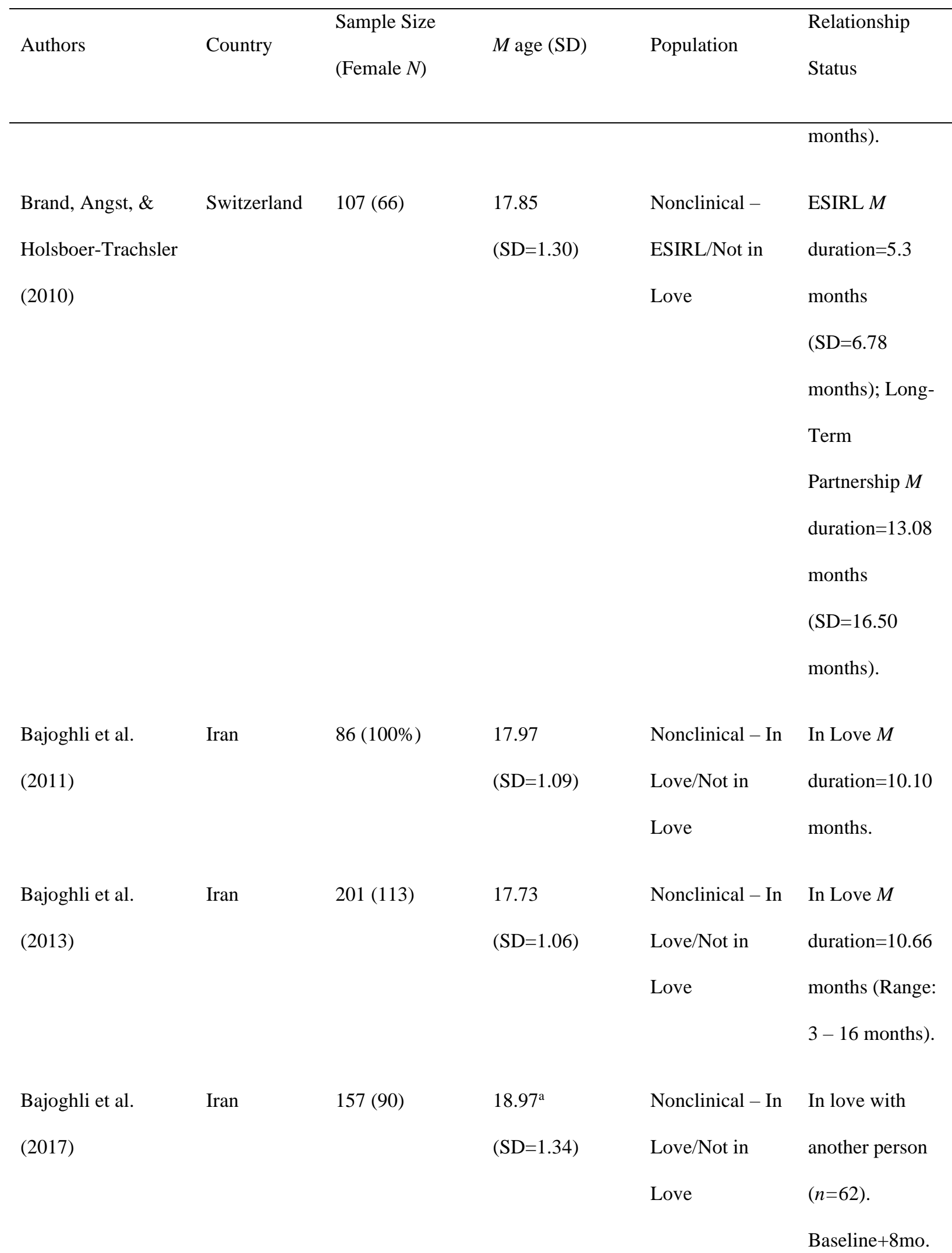




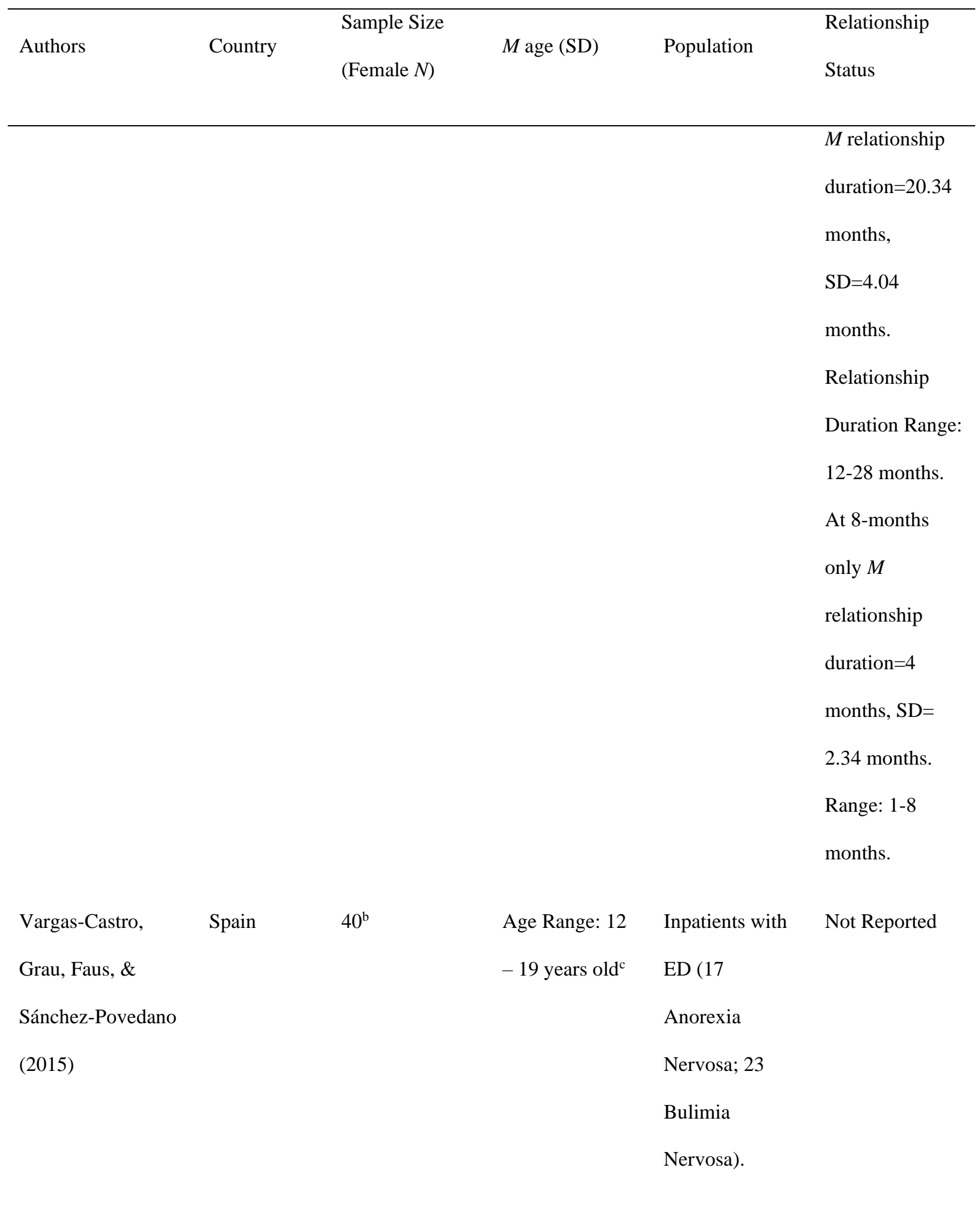

a) Participants had been recruited 8 months prior; $M$ age reflects age at follow-up.

b) Gender proportion was not reported.

c) Mean age was not reported; participants had been diagnosed $<18$ years old. 


\section{Prepublicaciones OpenCiencia}

Prepublicaciones OpenCiencia

ISSN 2708-8693

www.prepublicaciones.org

OpenCiencia

https://doi.org/10.47073/preprints. 12

\section{Table A2}

Literature Review Summary Findings: HCL-32 Use with Adolescents ( $n=8)$

\begin{tabular}{|c|c|c|c|c|c|c|}
\hline \multirow[b]{2}{*}{ Category } & \multirow[b]{2}{*}{ Authors } & \multirow[b]{2}{*}{ Method } & \multicolumn{3}{|c|}{ HCL-32 Properties and Results } & \multirow[b]{2}{*}{ Relevant Findings } \\
\hline & & & Total & $\begin{array}{l}\text { Active/Elated } \\
(\mathrm{A} / \mathrm{E})\end{array}$ & $\begin{array}{l}\text { Risk- } \\
\text { Taking/Irritability } \\
\text { (RT/I) }\end{array}$ & \\
\hline \multirow[t]{10}{*}{ Psychometric } & Holtmann & Cross-Sectional. & German version, no & $\mathrm{A} / \mathrm{E}$ & Subdivided in two: & Severity and impact items were not \\
\hline & et al. & Exclusion: Missing & modifications & Cronbach's & Disinhibited/Stimul & well understood by adolescents. The \\
\hline & (2009) & biological sex data & (Cronbach's $a=0.71$ ). & $a=.68$ & ation Seeking & A/E subscale identified adolescents \\
\hline & & $(n=2)$ and more than 3 & Duration and & Hypomanic. & (D/SS; Cronbach's & who did not view their symptoms as \\
\hline & & missing items $(n=5)$ & functional impact & $M=9.0$ & $a=.58)$ and & pathological. D/SS was associated to \\
\hline & & Principal components & items $(n=8)$ were & $(\mathrm{SD}=1.55)$ & Irritable-Erratic (I-E & less inhibited behavior, increased \\
\hline & & analysis performed with & rated. Most & Non- & $a=.58)$. Hypomanic & substance use and sexual activity. I-E \\
\hline & & Kaiser's Varimax & frequently & Hypomanic. & D/SS. $M=3.8$ & was associated to distractibility and \\
\hline & & rotation. Hypomania & unreported items: 7 & $M=8.5$ & $(\mathrm{SD}=1.57)$; Non- & poor self-regulation. Generalizability \\
\hline & & assessed with DSM-5 & ("I tend to drive & $(\mathrm{SD}=2.15$ & Hypomanic D/SS. & limited by non-clinical adolescents. \\
\hline
\end{tabular}


HCL-32 Properties and Results

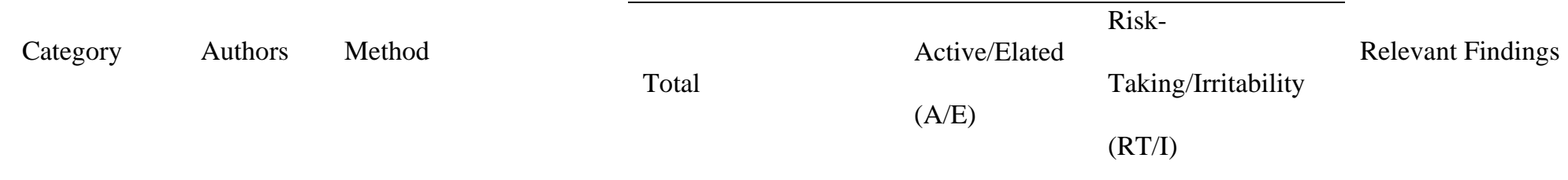

$\begin{array}{ll}\text { duration criteria (>4 } & \text { faster"), } 16 \text { ("I am } \\ \text { days) and negative } & \text { more interested in } \\ \text { reactions from others. } & \text { sex"), and } 17 \text { ("I am }\end{array}$

Co-assessments: SDQ more flirtatious").

Hypomanic (n=23).

Total score $M=18.3$

$(\mathrm{SD}=3.78)$. Non-

NS).

$M=2.8(\mathrm{SD}=1.64$;
$p<.01)$. Hypomanic

I-E. $M=5.6$

( $\mathrm{SD}=2.29)$; Non-

\section{Hypomanic I-E.}

$M=4.6(\mathrm{SD}=2.44 ;$

NS).

Hypomanic (n=182).

$M=15.8(\mathrm{SD}=4.32 ;$

$p=.01$ ).

\begin{tabular}{|c|c|c|c|c|c|c|}
\hline Psychometric & Hosang, & Cross-Sectional (Phase & HCL-32, reduced & Cronbach's & Cronbach's $a=.42$. & Total scores correlated positively \\
\hline & Cardno, & 2 of the LEAP & items (HCL-16, Forty & $a=.67 . \mathrm{BD}$ & Correlated with: & with extraversion, openness to \\
\hline & Freeman, & longitudinal study). & et al., 2010; & Family & SDQ - Emotional & experience, substance use in the last \\
\hline & \& Ronald & Exclusion criteria: & Cronbach's $a=.66$.). & History. $t$ & Problems $\mathrm{z}=3.79, p$ & 12 months, sleep problems and \\
\hline & (2017) & Severe medical & Cut-off score $=8$. & $(1395)=1.99$ & $<.002$. Hyperactive & sensitivity to anxiety. Risk-taking \\
\hline & & disorder, history of & Most frequently & $p=.047$. SPEQ & $\mathrm{z}=5.30, p<.002$. & items loaded in the $\mathrm{A} / \mathrm{E}$ dimension. \\
\hline
\end{tabular}


HCL-32 Properties and Results

\begin{tabular}{|c|c|c|c|c|c|c|}
\hline \multirow{3}{*}{ Category } & \multirow{3}{*}{ Authors } & \multirow{3}{*}{ Method } & \multirow[b]{3}{*}{ Total } & \multirow[b]{2}{*}{ Active/Elate } & & \multirow[b]{2}{*}{ Relevant Findings } \\
\hline & & & & & NIDS & \\
\hline & & & & $(\mathrm{A} / \mathrm{E})$ & Taking/Irritability & \\
\hline
\end{tabular}

$\begin{array}{llll}\text { severe perinatal } & \text { endorsed items: } & \text { Anhedonia } & \text { Conduct Problem } \\ \text { complications, } & \text { More optimistic, less } & \mathrm{z}=2.14, & \mathrm{z}=4.85, p<.002 ; \\ \text { unknown zygosity. Co- } & \text { shy or inhibited. Less } & p=.032 . & \text { Peer Problems } \\ \text { assessments: SMFQ, } & \text { endorsed: "Smoking } & \mathrm{z}=5.52, p<.002 ; \\ \text { CASI, SPEQ, PLIKS-Q, } & \text { more cigarettes" and } & \text { Lower Life } \\ \text { PSQI, FFM, Family } & \text { “Taking more drugs". } & \text { Satisfaction } \mathrm{z}=- \\ \text { history of BD [by } & \text { Total } \boldsymbol{M} \text { score=7.12 } & 4.99, p<.002 . \\ \text { parent report], Yes/No } & \text { (SD=2.60). } N=673 & \\ \text { 15-substance abuse } & \text { hypomanic (47\%). } & \\ \text { questionnaire. } & \text { 124 (9\%) participants } & \\ & \text { had a total score over } & \\ & \text { 8, with negatively } & \\ & \text { impacting symptoms } & \\ & \text { lasting more than 2 } & \\ & \text { days. }\end{array}$


HCL-32 Properties and Results

$\begin{array}{llll} & & & \text { Risk- } \\ \text { Category } & & \text { Active/Elated } & \text { Taking/Irritability } \\ \text { nethors } & \text { Total } & \text { (A/E) }\end{array}$

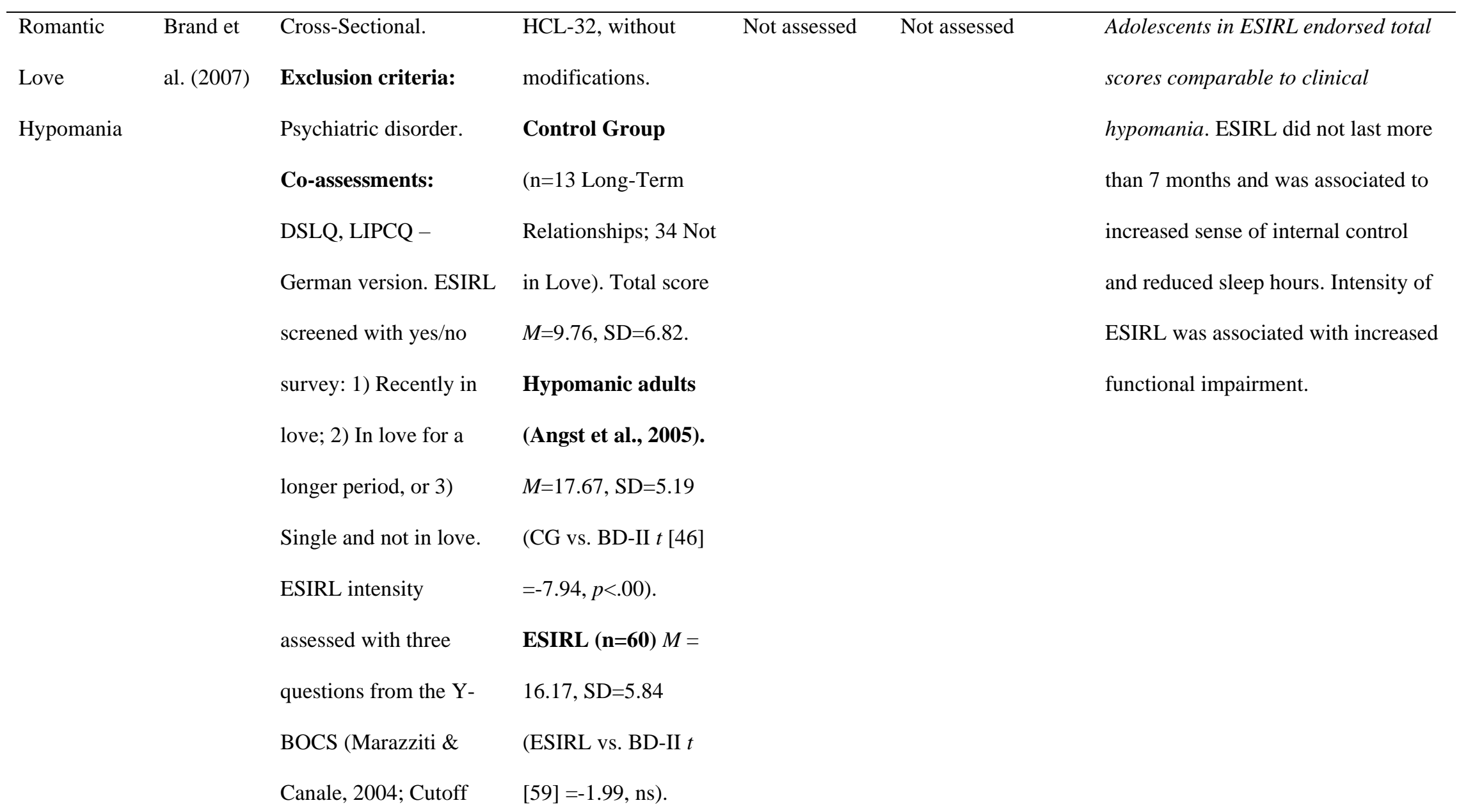


HCL-32 Properties and Results

\begin{tabular}{llll}
\cline { 3 - 3 } Category & & Risk- & Active/Elated \\
Taking/Irritability & Total & (A/E) & (RT/I)
\end{tabular}

score $=6$ ).

\begin{tabular}{|c|c|c|c|c|c|c|}
\hline Romantic & Brand, & Cross-Sectional. & HCL-32, without & BD-II (Angst & Group & ESIRL HCL-32 total scores were \\
\hline Love & Angst, \& & Exclusion criteria: & modifications. & et al., 2005) & Differences. BD-II & comparable to adult outpatients with \\
\hline \multirow[t]{11}{*}{ Hypomania } & Holsboer- & Psychiatric disorder & Gender differences. & $M=12.49$ & $M=2.82, \mathrm{SD}=1.82$ & BD-II. Female adolescents had \\
\hline & Trachsler & (Screened with MINI, & Total score $F(1,103)$ & $(\mathrm{SD}=4.36)$ & ESIRL $M=3.82, \mathrm{SD}$ & significantly higher total and RT/I \\
\hline & $(2010)$ & VZDS, and STAI). & $=5.64, p=.019$ & ESIRL & $=1.72 ; \mathrm{CG}=3.43$ & symptoms. Adolescents overall had \\
\hline & & ESIRL was screened via & Group Type $x$ & $M=9.83$ & $\mathrm{SD}=1.98$. Gender & higher RT/I symptoms than adult BD- \\
\hline & & yes/no survey and co- & Gender. Total score & $(\mathrm{SD}=4.19)$ & differences. $F(1$, & II outpatients. Adults with BD-II had \\
\hline & & assessed with the $\mathrm{Y}$ - & $F(1,103)=24.47$ & CG $M=6.02$ & $103)=9.40, p=.003$. & significantly more A/E symptoms. \\
\hline & & BOCS (Cut-off score $=$ & $p=.000)$ & $(\mathrm{SD}=4.65)$ & & \\
\hline & & 6 discriminates "in & & Group Type x & & \\
\hline & & love" vs "highly in & & Gender. $F(1$, & & \\
\hline & & love"). & & $103)=30.50$ & & \\
\hline & & & & $p=.000$. & & \\
\hline Romantic & Bajoghli & Cross-Sectional. & HCL-32, Farsi & Not assessed & Not assessed & Adolescents in love reported more \\
\hline Love & et al. & Romantic love was & version, without & & & hypomanic symptoms and increased \\
\hline
\end{tabular}


HCL-32 Properties and Results

\begin{tabular}{llcl}
\cline { 3 - 3 } Category & & Risk- & Active/Elated \\
Taking/Irritability
\end{tabular}

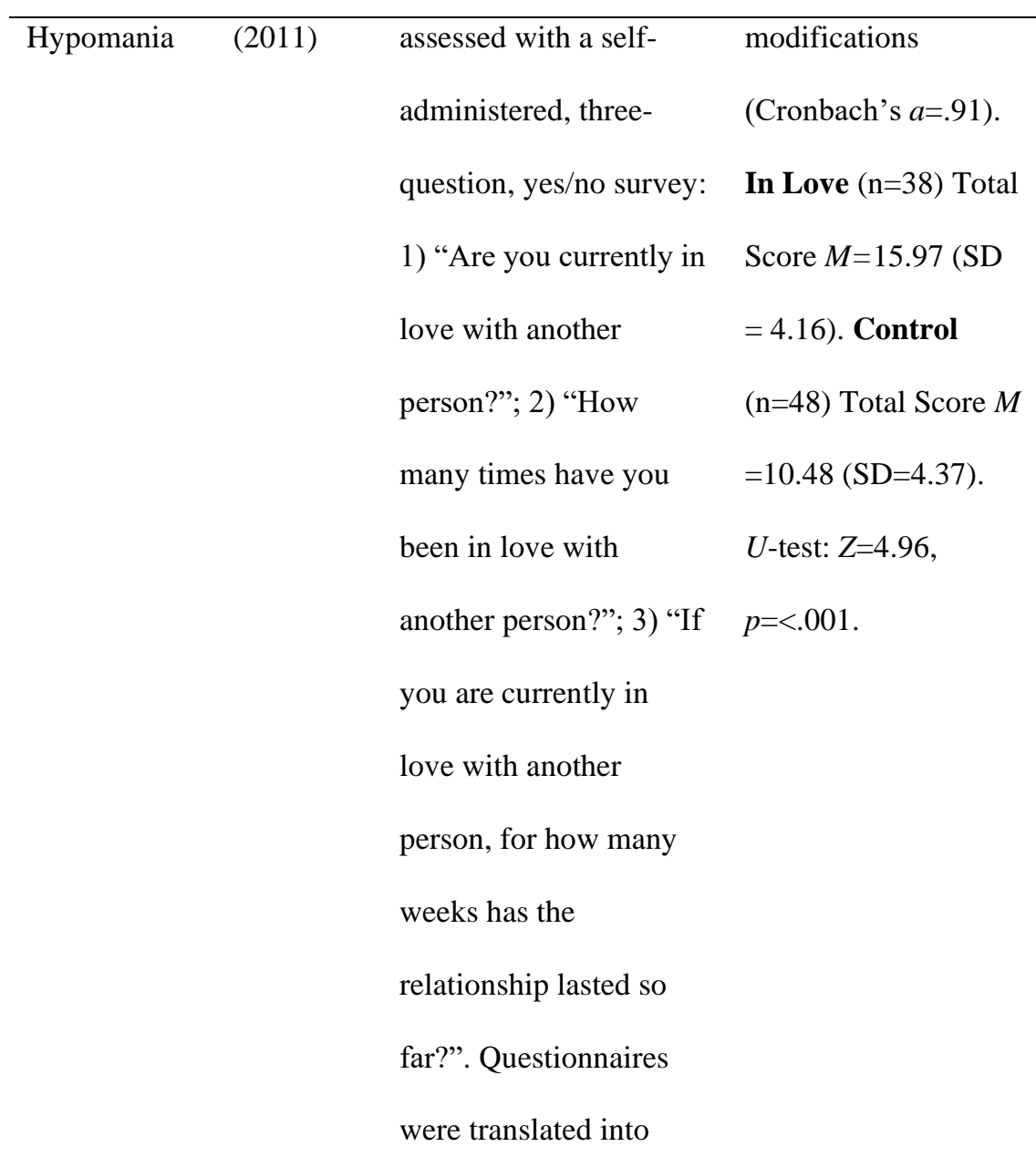

physical activity, had improved

concentration during the day and more positive evening moods. No significant inter-group differences were found for sleep or depression symptoms. Hypomania scores increased with relationship duration. 
HCL-32 Properties and Results

$\begin{array}{llll} & & & \text { Risk- } \\ \text { Category Authors } & \text { Active/Elated } & \text { Taking/Irritability } \\ & & \text { (A/E) } & \text { (RT/I) }\end{array}$

Farsi with Brislin's

method (1986). Co-

assessments: VZDS,

DSLQ, 7-Day Exercise

$\log$.

\begin{tabular}{|c|c|c|c|c|c|c|}
\hline Romantic & Bajoghli & Cross-Sectional. ESIRL & HCL-32, Farsi & Female in & Female in Love $M$ & In love adolescent group reported \\
\hline Love & et al. & assessed via self- & version, without & Love $M=$ & $=7.24, \mathrm{SD}=3.78$ & elevated mood, improved \\
\hline \multirow[t]{9}{*}{ Hypomania } & (2013) & administered, three- & modifications. & 12.01 & Female Not in & concentration, less depression \\
\hline & & question, yes/no survey. & Female in Love & $(\mathrm{SD}=2.05)$ & Love $M=9.15, \mathrm{SD}$ & symptoms and increased state \\
\hline & & Other assessments: & $(\mathrm{n}=48) M=19.25$ & Female Not in & $=2.90$. Male in & anxiety. Romantic love state \\
\hline & & VZDS, STAI, DSLQ, 7- & $(\mathrm{SD}=4 \cdot 10)$. Female & Love $M=9.21$ & Love $M=8.20(\mathrm{SD}$ & correlated positively with hypomania \\
\hline & & Day Exercise Log & Not in Love $(n=65)$ & $(\mathrm{SD}=3.25)$ & $=3.01)$. Male Not & only. \\
\hline & & & $M=18.36(\mathrm{SD}=3.78)$ & Male in Love & in Love $M=10.42$ & \\
\hline & & & Male in Love $(n=33)$. & $M=10.98(\mathrm{SD}$ & $(\mathrm{SD}=3.77)$ & \\
\hline & & & $M=19.18(\mathrm{SD}=5.42)$ & $=4.38)$. Male & ANOVA Gender $F$ & \\
\hline & & & Male Not in Love & Not in Love & $(1,197)=.006$ & \\
\hline
\end{tabular}


HCL-32 Properties and Results

\begin{tabular}{|c|c|c|c|c|c|}
\hline \multirow{4}{*}{ Category } & \multirow{4}{*}{ Authors } & \multirow{4}{*}{ Method } & \multirow{2}{*}{\multicolumn{3}{|c|}{ Risk- }} \\
\hline & & & & & \\
\hline & & & \multirow[b]{2}{*}{ Total } & Active/Elated & \multirow[t]{2}{*}{ Relevant Findings } \\
\hline & & & & $(\mathrm{A} / \mathrm{E})$ & \\
\hline
\end{tabular}

$(\mathrm{n}=55) . M=19.14$

$(\mathrm{SD}=5.75)$. ANOVA $(\mathrm{SD}=4.92)$

Gender $F(1,197)$

$=.28, p=.001$.

\section{ANOVA}

Gender $F(1$,

197) $=1.95, p$

$=.003$.

Romantic

Bajoghli

Cross-sectional; follow-

up at 8 months

HCL-32, Farsi

version, without

Hypomania

et al.

(Bajoghli et al., 2013).

modifications

ESIRL assessed via

\section{INLOVESTABLE}

self-administered, three-

$(\mathrm{n}=45)($ In love at

question, yes/no survey. baseline and follow-

Co-assessments: STAI, up): Baseline

VZDS, DSLQ
$M=20.91(\mathrm{SD}=4.20)$;

Follow-up $M=16.21$

$(\mathrm{SD}=2.81)$.

\section{Not assessed Not assessed}

Four patterns of hypomanic

symptoms correlated with romantic

love status, mood, and anxiety at 8 -

month follow-up. "Newly in love"

had increased hypomania and state

anxiety. Hypomanic scores decreased

for those still in love at 8 months.

Sleep pattern did not differ between

groups. 
HCL-32 Properties and Results

Category Authors Method

$\begin{array}{ll}\text { Active/Elated } & \text { Taking/Irritability } \\ (\mathrm{A} / \mathrm{E}) & (\mathrm{RT} / \mathrm{I})\end{array}$

Total

(RT/I)

\section{NOTINLOVESTAB}

LE (n=69) (Not in

love at baseline or

follow-up): Baseline

$M=18.32(\mathrm{SD}=4.52)$

Follow-Up $M=19.01$

(4.88).

\section{NEWLYINLOVE}

$(n=17)$ Baseline

$M=17.47(\mathrm{SD}=2.99)$;

Follow-Up $M=24.20$

$(\mathrm{SD}=1.15)$

\section{NOTANYMOREIN}

LOVE (n=19)

Baseline $M=20.36$

$(\mathrm{SD}=2.30)$, Follow- 
HCL-32 Properties and Results

$\begin{array}{llll}\text { Category Authors } & & \text { Risk- } & \text { Active/Elated } \\ \text { Taking/Irritability } & \text { Total } & \text { (A/E) } & \text { (RT/I) }\end{array}$

\section{Up $M=16.47$}

$(\mathrm{SD}=4.26)$.

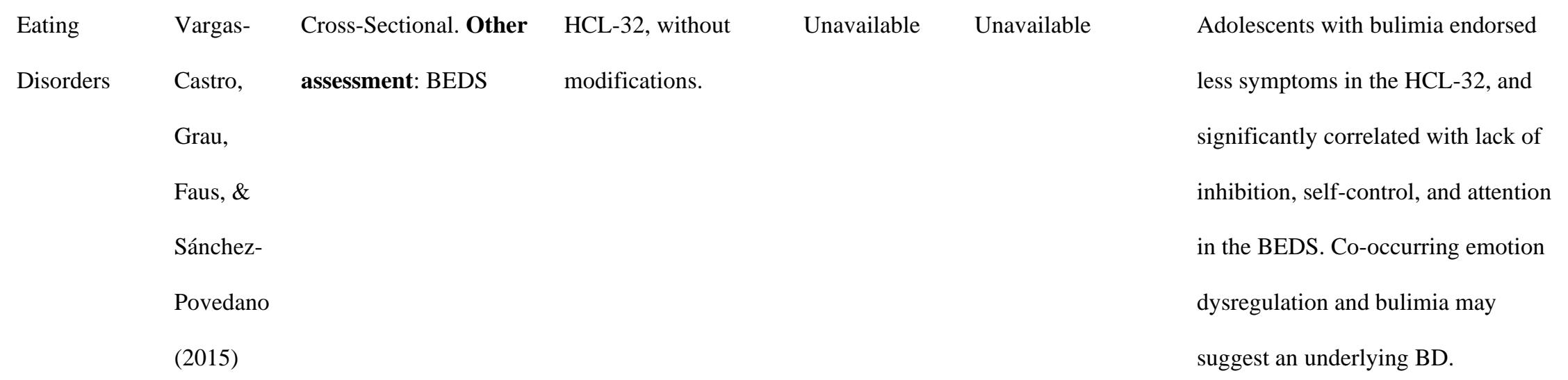

d) Abbreviations: Barcelona-Bipolar Eating Scale (BEDS), Child Anxiety Sensitivity Index (CASI), Daily Sleep Log Questionnaire (DSLQ), Five-Factor Model (FFM), Hypomania Check List - 32 (HCL-32), Levenson’s IPC Questionnaire (LIPCQ), Mini International Neuropsychiatric Interview (MINI), Pittsburgh Sleep Quality Index (PSQI), Psychotic-Like Symptoms Questionnaire (PLSQ), Specific Psychotic Experiences Questionnaire (SPEQ), StateTrait Anxiety Inventory (STAI), Short version of the Moods and Feelings Questionnaire (SMFQ), Strengths and Difficulties Questionnaire (SDQ), Von Zerssen's Depression Scale (VZDS), Yale Brown Obsessive-Compulsive Scale (Y-BOCS) 


\section{Figure 1A}

Schematic of the Systematic Literature Review Inclusion/Exclusion Process

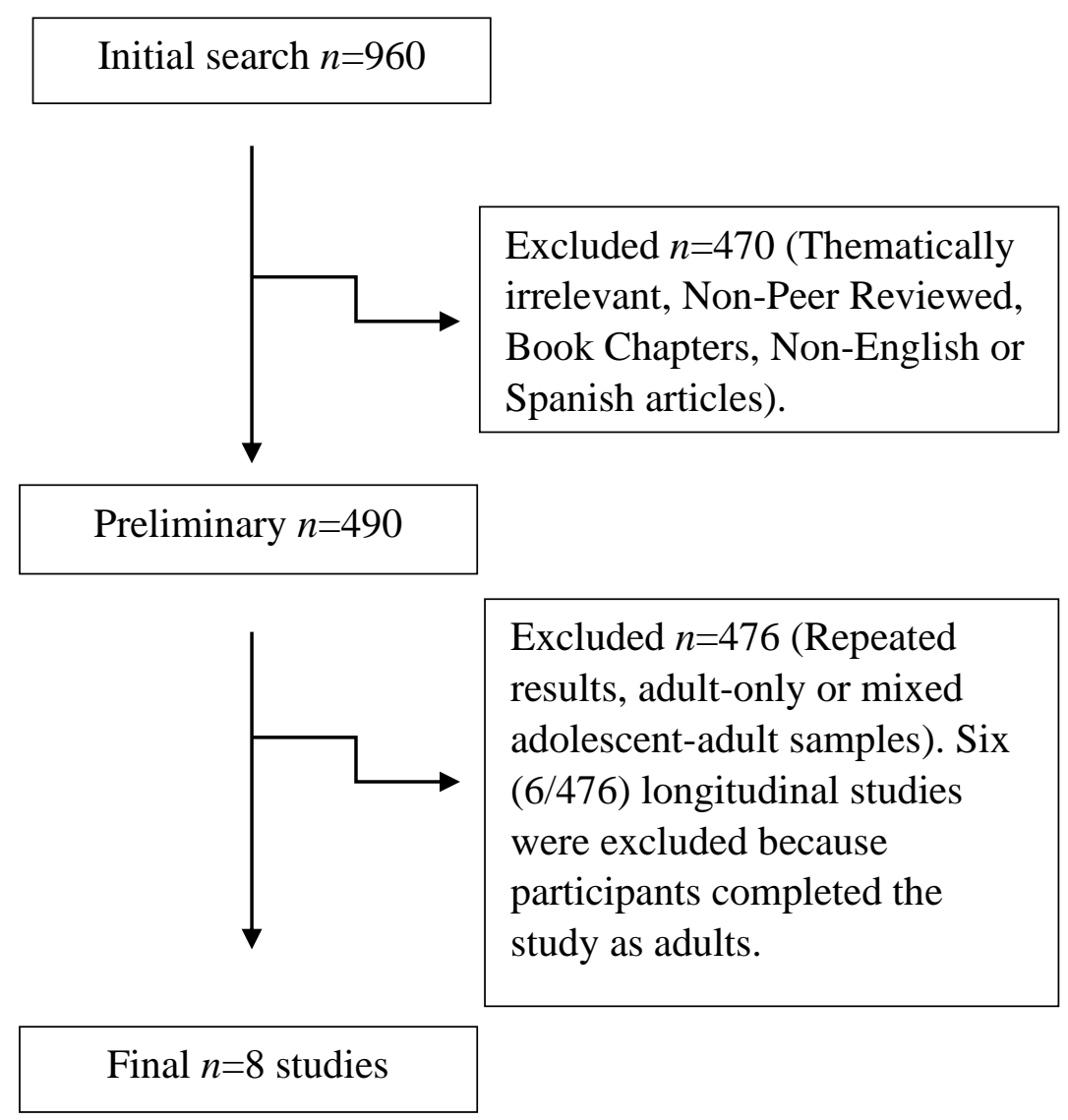

Note. Included publications were classified according to thematic focus and their references parsed for additional, potentially eligible studies. 


\section{Figure 2A}

\section{Recommended HCL-32 Screening Process with Adolescents}

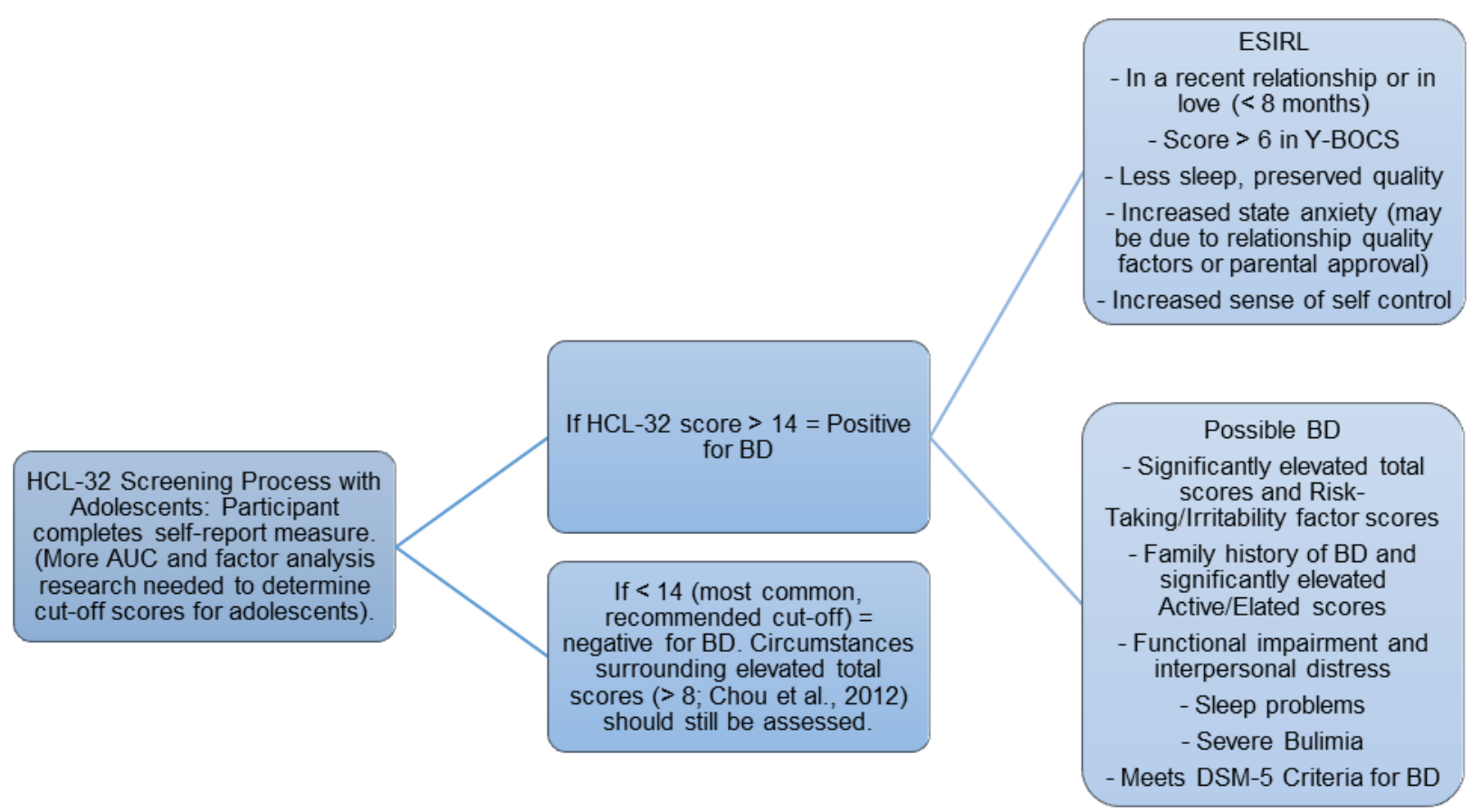

Note. A cut-off score of 14 confers the most balance between specificity and sensitivity (Angst et al., 2005). Because adolescents tend to endorse more irritable/risk-taking symptoms, an assessment of the optimal cut-off score for this population is suggested. 


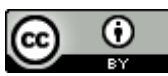

This text is under a Creative Commons BY 4.0 license

You are free to Share - copy and redistribute the material in any medium or format - and Adapt the content - remix, transform, and build upon the material for any purpose, even commercially under the following terms:

Attribution: You must give appropriate credit, provide a link to the license, and indicate if changes were made. You may do so in any reasonable manner, but not in any way that suggests the licensor endorses you or your use. 